
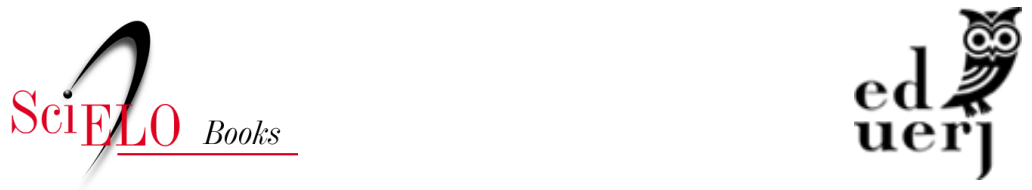

\title{
O campo etnográfico
}

Maria Cláudia da Veiga Soares Carvalho

\section{SciELO Books / SciELO Livros / SciELO Libros}

CARVALHO, M. C. V. S. O campo etnográfico. In: Bricolagem alimentar nos estilos naturais [online]. Rio de Janeiro: EDUERJ, 2013, pp. 47-63. ISBN: 978-65-88808-07-8.

https://doi.org/10.7476/9786588808078.0005.

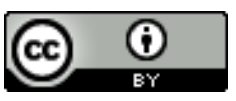

All the contents of this work, except where otherwise noted, is licensed under a Creative Commons Attribution 4.0 International license.

Todo o conteúdo deste trabalho, exceto quando houver ressalva, é publicado sob a licença Creative Commons Atribição 4.0.

Todo el contenido de esta obra, excepto donde se indique lo contrario, está bajo licencia de la licencia Creative Commons Reconocimento 4.0. 


\section{O campo etnográfico}

\section{Consideraçóes sobre a metodologia}

De que mundo estamos falando?

Um mundo de símbolos, ações, comportamentos, interações verbais, modo de fazer, estar e dizer, situações inusitadas e cotidianas, ritmos de vida e de acontecimentos. Mundo de discursos e ritmos do falar, de tom e intensidade de voz, hesitaçôes, silêncio, gestos paralelos, olhares, postura e movimentos. O método orientou estratégias sensíveis para informaçōes verbais e não verbais, assim como para impressões e estados de espírito: "Um método é uma estratégia integrada de pesquisa que organiza criticamente as práticas de investigação, incidindo nomeadamente sobre a seleção e articulação das técnicas de recolha e análise da informação" (Costa, 2003, p. 129).

A coleta e o registro de material no campo contaram com a observação direta do investigador para vivenciar comportamento, discurso, acontecimentos, práticas e narrativas que, de outra forma, poderiam ficar imperceptíveis ou se mostrar irrelevantes e se perder, caso o pesquisador não estivesse presente, interagindo com a população. Portanto, sua presença foi o principal instru- 
mento, de modo não pontual, para que fosse possível a percepção de disposições duráveis nas práticas.

Nesse processo, privilegiar a informalidade foi inevitável porque permitiu um ajustamento entre observador e o que é observado com menor interferência de seu papel, pois, caso a presença do pesquisador fosse autoritária ou formal, a convivência poderia ficar mais difícil, pois ele não se tornaria parte do campo. "Nos aspectos práticos, é só no convívio com o cotidiano cultural que se obtêm os elementos que constituem um fato, que separam um fenômeno de outro e definem a estrutura e o processo específicos daquilo que constitui a vida social dum grupo" (Iturra, 2003, p. 157). Com essa finalidade, fizemos observação participante continuada, o que nos proporcionou uma aproximação dos sujeitos em suas práticas, nos protegeu de uma imposição e permitiu ajustes e adequações ao longo do tempo. No campo, as relaçôes se reorganizam continuamente com a presença do investigador, o que dá a ele a oportunidade de se adaptar a elementos e regras que fazem parte do jogo simbólico, compreendê-los e identificar informantes privilegiados.

O olhar do pesquisador seleciona os elementos no campo; o registro de material será produto, ao mesmo tempo, do que ele é capaz de ver e do que se mostra a ele no campo. Há reações postas no campo e captadas por ele que são uma forma de esse campo "se mostrar". Segundo Costa, o que o pesquisador pensa, o que quer, o que teme são fontes "extremamente significativas de informação sobre os quadros de representações, os sistemas de classificações, os valores, as normas, os sistemas de status e de papéis sociais, as táticas do relacionamento cotidiano" (2003, p. 138). Algumas informações mais aprofundadas sobre as escolhas alimentares foram parte de outra técnica, a entrevista informal.

O tipo de resposta que a entrevista nos deu não foi necessariamente a uma pergunta; a entrevista informal não é feita somente de respostas a perguntas. "Pode dizer-se que a pesquisa 
de terreno é, em boa medida, a arte de obter respostas sem fazer perguntas" (p. 138). As entrevistas informais não foram estruturadas, nem seguiram um questionário-guia. Visaram aprofundar a relação com informantes para recolha de normas e classificações, de status e preferências que distinguiam elementos do campo que estávamos analisando e tinham origem no passado. Os entrevistados foram selecionados a partir do próprio trabalho de campo, da familiarização do pesquisador com o campo; a seleção foi feita na observação participante. Alguns entrevistados indicavam os outros, explicitamente ou não, o que os legitimava no contexto vegano, naturalista ou de alimentação viva.

As entrevistas não seguiram um padrão em relação ao local dos restaurantes e das feiras ou a um roteiro de assuntos ou perguntas. Algumas foram feitas nos núcleos familiares dos entrevistados; outras, nos restaurantes; umas, em grupos; outras, individualmente. Os assuntos foram diversos, e mesmo a apresentação de minha posição de pesquisadora se diversificou, pois alguns demonstravam mais interesse em minha vida do que outros. Algumas entrevistas foram feitas em partes, em virtude de minha convivência continuada em certos locais; às vezes tínhamos de interrompê-las, mas conseguíamos retomá-las em outro momento. Todas as entrevistas informais se transformaram em textos que foram devolvidos para que os entrevistados pudessem autorizar o uso do material escrito. Eles podiam modificar o texto livremente, caso quisessem; depois assinavam o termo de consentimento, espécie de acordo social que marcou uma relação ética no campo. Compreendemos que, dessa forma, nossos laços se estreitavam, aumentando o respeito mútuo, o sentimento de cooperação e o interesse em participar da pesquisa e se sentir ativo no processo. Muitas vezes, meu retorno com o texto da entrevista permitiu acertos e esclarecimentos importantes, analisados e interpretados no processo de pesquisa. 
A maior parte dos entrevistados foi composta de adultos; somente uma entrevistada era da faixa mais jovem. Não buscamos comparar gerações nem analisar tendências seculares, embora em muitas entrevistas tenhamos coletado dados e relatos sobre o passado dos entrevistados, sua juventude e as memórias dos anos 1970 e 1980. A perspectiva foi muito mais antropológica do que histórica, com intenção de analisar memórias incorporadas com sentimentos que duram até hoje, momento da entrevista, numa busca pelo "como é que éramos quando não éramos o que hoje somos" (Iturra, 2003, p. 151).

Se, por um lado, a observação participante e a entrevista informal ganham na dimensão da interação direta com os agentes, por outro, são limitadas para a análise de elementos contextuais das situações lembradas. Assim, consideramos relevante a coleta de documentos pessoais e informais complementares à observação direta na "caracterização de opiniōes, expectativas, quadros de valores e visões do mundo dos sujeitos sociais. São auxiliares da construção de genealogias e histórias de vida ou biografias, procedimentos correntes e de grande utilidade na pesquisa de terreno" (Costa, 2003, p. 141). São dados obtidos pelo entrevistador que não fizeram parte do discurso, nem de seu comportamento, mas que delimitaram o campo no que ele tem incorporado do passado. Quando um entrevistado me trazia suas anotações ou algum material, trazia também intençóes e impressões de outro momento histórico para o contexto da entrevista. Esse material coletado no campo foi disponibilizado para análise na categoria de documentos informais.

Vários entrevistados me mostraram ou copiaram para me dar recortes de jornal, entrevistas suas passadas, notícias antigas sobre vegetarianos e novidades sobre o assunto, propostas e projetos de trabalho pessoal, panfletos com mensagens educativas e religiosas, fôlderes comerciais, livros, certificados, fotos etc. Fizeram parte desse grupo de documentos os registros fotográficos de mo- 
radias e restaurantes, além de detalhes considerados importantes que foram aparecendo no decorrer do trabalho de campo.

A revisão bibliográfica buscou na literatura científica tanto atualização quanto fundamentação teórica. A atualização teve como finalidade uma aproximação de outros trabalhos, na interface das ciências humanas e da saúde, sobre sentidos e significados e contou com o banco de dados virtual Biblioteca Virtual em Saúde (Bireme) e o acesso a bibliotecas e livrarias. As quatro técnicas buscaram dar conta do que Bourdieu (1980b) chama de conhecimento das condiçóes de conhecimento do investigador com o objeto, abrindo um caminho para sua construção na pesquisa.

\section{Os passos da investigação no campo de pesquisa}

Os locais mais frequentados foram aqueles em que se consumia ou comercializava uma alimentação reconhecida como natural. Minhas experiências numa associação de produtores de alimentos orgânicos abriram o caminho.

A escolha pelos restaurantes ocorreu graças ao espaço marcante que o comer-fora-de-casa vem ocupando na vida urbana; além disso, feiras e hortomercados foram muito visitados. Existe uma motivação crescente no espaço público para uma alimentação natural. Os pontos escolhidos para observação foram variados, em geral pontos comerciais representativos de uma classe média urbana carioca. Alguns restaurantes eram prolongamentos das casas dos proprietários. Não citamos seus nomes por causa da proximidade que estabelecemos com eles no decorrer dos quatro anos do doutorado; no entanto, não evito a indicação dos entrepostos comerciais que têm interesse de serem visitados.

O primeiro local visitado foi a COBAL do Humaitá, espécie de hortomercado que existe há aproximadamente quarenta anos e fica entre as ruas Voluntários da Pátria e São Clemente, em Botafogo. COBAL é a abreviação de Companhia Brasileira de 
Alimentos, empresa pública que surgiu em 1962 para substituir o Serviço de Assistência da Previdência Social (SAPS) e exercer atividade de abastecimento de baixo custo por meio de supermercados destinados à população em geral. Em seguida, foi fundida a outras empresas, originando a Companhia Nacional de Abastecimento (CONAB), mas a denominação COBAL foi mantida e se consolidou como ponto comercial (e de encontro) da classe média carioca que une variados produtos de modo informal. Embora o papel do Estado tenha sido fundamental na constituição da COBAL, hoje é relativo, pois, segundo alguns comerciantes, esse mercado vive um abandono do poder público, sem política alguma para organizar o espaço.

O local possui características típicas de um ponto de encontro do carioca por reunir grande variedade de bares e restaurantes, peixaria, açougue, lojas de vinho e conveniência, de flores, decoração e vestuário, além do próprio mercado, que ainda funciona em boxes, como uma feira de gêneros in natura e orgânicos, e que, apesar de ter perdido espaço, ainda continua presente como bom comércio de hortaliças e frutas. Trata-se de um espaço marcado pela informalidade, pela diversidade e por um clima de boa vizinhança. Para o carioca, já estereotipado como aquele que convida para sua casa, mas não dá o endereço, a COBAL é perfeita para certo descompromisso desse ethos, pois os encontros acontecem no ir e vir cotidiano em bares e restaurantes simpáticos e aconchegantes, com comidas diversificadas, a um custo razoável para a classe média.

Numa análise mais estética, em perspectiva gráfica, esse espaço mistura aspectos artesanais - a tipografia manual com saudaçōes e mensagens familiares - e industriais - expressos em designs mais elaborados. No trabalho de campo, priorizamos um restaurante vegano, um box de alimentos orgânicos, que abriga componentes da Associação de Agricultores Biológicos do Estado do Rio de Janeiro (ABIO), e lojas de produtos naturais. 
Selecionamos restaurantes veganos especializados sem um critério estatístico; por isso, não ampliamos o campo em número de restaurantes ou de visitas a eles - investimos na intensidade das observações. Esses restaurantes representam um espaço constituído para divulgação de um estilo de vida. Em vários, o responsável desenvolve curso de culinária para mostrar que é possível a qualquer pessoa fazer refeiçóes saborosas somente com o alimento de origem vegetal. São locais de encontro de veganos.

A região mais visitada foi a Zona Sul: em Botafogo, visitamos o Vegan Vegan, o Rio Vegetariano, o Refeitório Orgânico e a Pensão Vegetariana; no Leblon, o Universo Orgânico. Já no Centro, o Metamorfose e o Reino Vegetal. Esses locais tinham muitos pontos em comum. Todos são considerados pequenos comércios que vendem acessórios para uma alimentação diferenciada; alguns, de camiseta e utensílios de cozinha a alimento in natura para levar e fazer uma alimentação vegana ou natural em casa. Divulgam eventos e distribuem impressos com informações e orientações para atividades com fins terapêuticos, como ioga, tai-chi-chuan, massagens etc. Todo esse material foi disponibilizado para análise como documentos informais.

Fizemos campo também em Vargem Grande por causa de dois restaurantes, o Natuwal e o Caminho do Mar, que nos foram indicados por entrevistados e usuários, e por considerar esse bairro um pequeno núcleo de adeptos do estilo natural e vegano. Uma entrevistada teve uma casa de produtos naturais quando Vargem Grande era menor, em que ela e o marido faziam pães integrais caseiros e difundiam o naturismo. Nesse bairro, existem cachoeiras, sítios, haras e trilhas pela mata. Boa parte de sua extensão é tomada pelo Parque Estadual da Pedra Branca, área de preservação ambiental, e mantém um clima de cidade pequena. O bairro é residência de vários artistas famosos que procuram um lugar mais tranquilo, com certa proximidade em relação à região mais central 
do Rio de Janeiro. É também onde residem dois grandes centros de montagem de programas de tevê: a Globo e a Record.

Aconteceram visitas informais no núcleo de alimento vivo denominado Terrapia e na produção de material desse projeto, situado na Escola Nacional de Saúde Pública (ENSP) Sérgio Arouca, no campus I da Fundação Oswaldo Cruz (Fiocruz), na Avenida Brasil, assim como em seu projeto parceiro nesse estilo de alimentação, o BIOCHIP, da Pontifícia Universidade Católica do Rio de Janeiro (PUC-Rio), no campus da Gávea. O Terrapia fica num pequeno terreno no campus da ENSP, bem arborizado, onde existem uma horta orgânica e uma cozinha preparada para dar cursos e eventos sobre alimentação viva.

Fizemos campo na Feira Orgânica da Glória, que acontece aos sábados das 8 às 13h, na Rua do Russel, na Praça Luiz de Camões, perto do Memorial de Getúlio Vargas. É uma feira pequena em relação ao padrão de feira livre de bairro, tem umas cinquenta barracas do mesmo tipo, de madeira com toldo vermelho - mas constituiu um núcleo de alimentação dos estilos vegan e vivo. Nela, são comercializados alimentos orgânicos in natura ou preparações, além de material considerado de suporte para esses estilos, como filtro ecológico de água, vinhos orgânicos e artesanato em geral. Algumas barracas ficam somente na exposição de material de divulgação, como a da Sociedade Brasileira Vegetariana, de defesa dos animais. Os alimentos comercializados têm sua procedência identificada para controle, são oriundos de sítios produtores do estado do Rio de Janeiro em sua maioria e fiscalizados pela $\mathrm{ABIO}$. A feira funciona como uma associação, cujo coordenador, Renato Martelleto, recebe uma cota de cada unidade para custear seu trabalho e pagar serviços, como um terceirizado que leva e traz todas as barracas. $\mathrm{O}$ coordenador tem a função de organizar eventos comemorativos (como festa junina, natalina e aniversários da feira) e administrar questōes burocráticas, como a licença da prefeitura. 
Em nosso trabalho de campo, não foi possível fazer observação participante em restaurantes veganos na periferia do Rio de Janeiro. $\mathrm{Na}$ realidade, não tivemos acesso a nenhum ponto para observação. Em geral, esse tipo de restaurante se concentra numa pequena área da cidade e não se expande para a periferia.

A Coonatura fez parte do campo de pesquisa por sua relevância como uma das primeiras iniciativas organizadas em defesa da agricultura orgânica e por concentrar material representativo de um universo imaginário do estilo de alimentação natural e vegano. Alguns de seus antigos participantes têm presença ativa na feira da Glória, cujo projeto foi gestado na cooperativa. Muitos entrevistados citaram alguma vivência nessa cooperativa, que se mostrou importante na construção desses estilos de alimentação.

Nascida em 1979, quando cooperativa ainda não representava espoliação para o trabalhador, a Coonatura era, de fato, uma cooperativa nos moldes de uma associação baseada na cooperação e no compartilhamento de interesses. Para se associar a ela, era preciso passar um tempo trabalhando com seus participantes a fim de conhecê-la. A iniciativa partiu de um pequeno grupo que se encontrou em evento informal realizado no Parque Lage, motivado por uma carta que o leitor Joaquim Moura enviou ao Jornal do Brasil. ${ }^{1}$ As pessoas que lá estiveram se organizaram para construir alternativas e soluções para o processo de industrialização acelerado. Propunham uma saída ecológica para uma crise e distribuíram informativos sobre comida sem veneno. Distribuíam também hortaliças frescas a baixo custo produzidas sem agrotóxicos. Ofereciam a quem tivesse fazenda, sítio ou mesmo terreno grande em casa apoio para hortas caseiras; era um modo de aumentar ou diversificar a renda, divertir-se, aprender plantando conforme a natureza e contribuir para a melhora da alimentação

1 Essas informações foram coletadas em duas entrevistas e documentos informais, no Jornal do Brasil de 28 de novembro de 1979 e no boletim da Coonatura. 
dos cariocas (Boletim Coonatura, 1994, n. 55). Ao final, davam o endereço de um apartamento em Copacabana para onde podiam ser enviadas cartas com adesão a essa proposta. O discurso de constituição da cooperativa era representativo de um imaginário que encantou a classe média.

\section{Quem é a classe média de nosso estudo?}

Nos termos de Bourdieu, os agentes sociais estão inseridos num campo que "é um mundo social e, como tal, faz imposiçoes, solicitaçôes etc., que são, no entanto, relativamente independentes das pressões do mundo social global que o envolve" (2003, p. 21); "[...] têm disposiçôes adquiridas [...], maneiras de ser permanentes, duráveis, que podem, em particular, levá-los a resistir, a opor-se às forças do campo" (p. 27).

No mundo ou contexto social, as forças e disposições se constituem como uma tessitura de fios e amarrações nas ações sociais concretas. Não necessariamente essas forças no campo seguem as pressões do mundo global, mas também não podemos concluir que os agentes estão livres delas. Um modo de ser classe média expressa um ethos dos agentes em sua reação às regras mais ou menos específicas de um jogo simbólico em seu campo de ação, queiram ou não, saibam ou não.

A delimitação de espaços físicos de restaurantes e mercados livres num contexto social de uma área nobre urbana configura um campo que relaciona aspectos diversos de um modo de ser de uma camada social, uma classe média carioca que é agente de práticas alimentares do estilo natural. Assim, classe média se tornou uma categoria de análise neste estudo e foi descrita em detalhes não somente físicos, mas também subjetivos, pois é compreendida nas relações sociais de seus agentes na prática.

Nos termos de Bourdieu, uma classe será construída e legitimada pelos agentes segundo regras de distinção elaboradas no 
contexto específico. O que chamamos de classe média é parte de uma paisagem social da cidade do Rio não como elemento transcultural, que existiria em si mesmo de modo anacrônico, nem de acordo somente com a renda ou o poder aquisitivo, mas como paisagem que respira, faz trocas simbólicas e aceita transformaçōes.

Essa classe média está delimitada pelo significado que atribui ao que possui ou seria capaz de possuir no contexto social urbano. Uma categoria de classe que não será definida pelo valor econômico de suas propriedades, "mas pela estrutura das relações entre todas as propriedades pertinentes que conferem seu valor próprio a cada uma delas [propriedades] e aos efeitos que ela exerce sobre as práticas" (Bourdieu, 1979, p. 117). Consideraremos propriedades, além dos bens materiais, o capital simbólico de que os agentes podem se apropriar nas práticas alimentares.

Estar numa mesma classe social significa estar numa situação com as mesmas probabilidades típicas de provisão de bens, posição social e construção de sentidos. Segundo Weber, "classe social chama-se a totalidade daquelas situaçôes de classe entre as quais um intercâmbio pessoal ou na sucessão de gerações é fácil, e costuma acontecer de modo típico" (1969, p. 242). ${ }^{2}$ Uma classe social comunga bases para uma ação social e para interesses por bens determinados pelo mercado econômico, mas não se orienta apenas por fins econômicos; orienta-se ainda por costumes, modos afetivos e interesses diversos determinados por valores de classe média.

O espaço social histórico de uma classe média remete ao nascimento de uma pequena burguesia que reorganizou uma estrutura de classes sociais. A classe média é considerada uma classe "de transição, que se define fundamentalmente por aquilo que não é mais e pelo que ainda não é, [e] extrai inúmeras atitudes [...] de uma posição de dupla oposição [...]" (Bourdieu, 1992, p. 9),

2 Weber faz distinção entre classe social, classe proprietária e lucrativa; no entanto, não iremos aprofundá-la aqui. 
oposição tanto a uma nobreza (elite) quanto às classes populares (população de baixo poder aquisitivo/ comunidades). É uma classe que historicamente condenou tanto o divertimento da "nobreza que não trabalha" quanto a indolência da mendicância da classe popular e que se estabelece construindo um estilo de vida original. Segundo Bourdieu, desenvolve uma "crença no valor da educação como instrumento de ascensão social” (p. 9) ou, segundo Weber (1989), uma crença de que a riqueza oriunda do trabalho é uma expressão da salvação divina, espécie de graça concedida.

Para Bourdieu, uma posição de classe está definida "menos por um ter do que por um ser, [embora] irredutível a seu ter, menos pela posse pura e simples de bens do que por certa maneira de usar esses bens" (1992, p. 16). A distinção social de classe na sociedade contemporânea está relacionada ao consumo, que diferencia as pessoas tanto pelo modo de consumir quanto pelos significados atribuídos àquilo que é consumível. A localização das habitaçôes na cidade e as paisagens urbanas distinguem os espaços de uma classe média, seguem uma hierarquia de valor, legitimado e atualizado pelos próprios agentes sociais.

A valorização das belezas naturais do Rio de Janeiro - praias, florestas tropicais com cachoeiras e lagoas - garante-lhe o título de Cidade Maravilhosa, atribuindo-se aos locais mais ou menos valor de acordo com essas belezas. No entanto, embora haja florestas, praias e lagoas em muitas partes, nem todas são muito valorizadas. As áreas mais valorizadas têm as belezas naturais bem conservadas e se restringem a menos de $50 \%$ da área total da cidade, localizando-se principalmente em partes do Centro, da Zona Sul, da Tijuca (no trecho do Alto da Boa Vista) e da Barra da Tijuca. A beleza desses lugares é mantida com investimentos da prefeitura em segurança pública, limpeza e urbanização, o que pode ser observado nos designs das calçadas das ruas, na preservação de parques e praças públicas, nas pistas para caminhadas e bicicletas, nos quiosques bem conservados, na arborização das ruas etc. 
A distinção social é construída no interior da própria classe média, no reconhecimento que os agentes desenvolvem dos elementos de diferenciação desse cenário de cidade maravilhosa. $\mathrm{O}$ distinto, que também é identificação de classe, está relacionado à estética dos prédios para moradia e à posição geográfica. Embora o tamanho dos apartamentos tenha diminuído em função de especulação imobiliária, crescimento populacional e urbanização acelerada, a funcionalidade foi se tornando um valor e aferindo distinção a um tipo de moradia de classe média. Os apartamentos grandes, do tipo "um por andar", foram dando lugar a condomínios ou prédios com muitas unidades e investimento num espaço comum de lazer. As cozinhas diminuíram, seguindo o modelo das americanas, e o fogão aos poucos vai sendo substituído pelo telefone, num claro incentivo aos serviços de delivery, com cada vez mais opções.

As pressões para diminuir o espaço de moradia se articulam a um mercado de trabalho a cada dia mais deteriorado, privatizado por desfiliação do Estado. Os apartamentos de classe média tendem a fazer a reversão das dependências de empregada para escritórios ou quartos de criança, adaptando-se para não abrir mão de bons pontos de moradia na cidade. A classe média se afina mais com apartamentos menores e funcionais nas áreas com mais belezas naturais do que com unidades maiores e mais confortáveis na periferia. Dessa forma, desenvolve estratégias de adaptação à concentração urbana e às pressões do mercado de trabalho. Segundo Giddens, a geografia e o ambiente das cidades refletem os sistemas sociais e econômicos de poder: "O formato físico das cidades é um produto das forças de mercado e do poder do governo" (2006, p. 461). A periferia do Rio costuma sofrer discriminação social, a começar pelo próprio abandono dos serviços públicos; salvo exceçôes, é considerada um local sem prestígio.

Não é com rigidez geográfica que delimitamos a área mais valorizada pela classe média; há locais da periferia que não se en- 
caixam nessa discriminação, como Vargem Grande, um dos muito visitados durante a pesquisa. $\mathrm{O}$ bairro é um lugar valorizado em virtude do estilo natural. Os entrevistados que lá moravam atribuíam distinção ao fato de ser um local dentro da cidade do Rio e ainda assim manter uma vegetação nativa, ser pouco urbanizado, com poucas construçôes e pouco comércio; como dizem alguns, "moro no mato e estou no Rio". Outros se referem à "vidinha vargem-grandense" com carinho, lembram que comiam "na casa da vizinha quando meu filho era pequeno e não dava para eu cozinhar em casa". Consideram o local um paraíso, atribuindo valor à sua tranquilidade e ao fato de poderem desenvolver ali uma "vida alternativa” à da cidade grande.

Os moradores entrevistados de Vargem Grande seguem também um padrão de classe média, com moradias intermediárias entre as grandes mansões da região e as construções populares. $\mathrm{O}$ mesmo ocorre com os restaurantes veganos e naturistas, opções aos do polo gastronômico. Vargem Grande reproduz uma vida classe média para alguns moradores graças ao fato de estes reconhecerem o bairro como parte original da Cidade Maravilhosa. Retomando Bourdieu (1979) no que diz respeito ao modo de consumir uma propriedade, a forma de consumir uma área verde em Vargem Grande confere um significado valorizado na prática por seus moradores.

Nesse contexto social de classe média, mais do que ter é preciso "saber usar" um bem de consumo. Não basta morar numa floresta; é preciso fazer disso um valor, incorporando os códigos identitários de um estilo de vida de classe média urbana. Da mesma forma, perto de Vargem Grande há belas praias. Mas não basta que a praia seja bela; é preciso que seja instituída socialmente como uma invenção que ganha um sentido social, com novas formas de sociabilidade, e que esse sentido seja reconhecido como distinção. Na prática, a praia está relacionada à informalidade e a certa malandragem do estilo de vida da classe média, meio despo- 
jado e ao mesmo tempo refinado do carioca. No caso dos naturistas, representa mais do que informalidade, mas a própria natureza em seu estado não civilizado, onde o homem está despojado, anda quase nu (em algumas praias da região, pratica-se o nudismo).

Em nosso estudo, observamos que o modo como se consome esse conceito de belezas naturais é um diferenciador de classes. A distinção social se apresenta na ideia de liberdade de escolha por esses locais belos; e, ainda que Vargem Grande seja uma opção mais barata à região nobre mais central do Rio, como a Zona Sul, a escolha é revestida de liberdade e se opõe à necessidade. Essa oposição nos elementos de interpretação é fundamental e tende a se impor, segundo Bourdieu (1979), como princípio homólogo norteador da situação social ou de classe. Em seu estudo sobre consumo de arte, cita a raridade/trivialidade ou facilidade de obter o que se deseja, defendendo que aquilo que é considerado comum tende à vulgaridade e se constitui em pares homólogos de significação. Na configuração de uma classe média, o par necessidade/luxo prevalece como norteador. O luxo está condicionado por uma sensação de liberdade de escolha, e a necessidade, pela falta de opção.

As práticas alimentares também são estruturantes e estruturadas da/pela classe média. Há uma disposição para um aspecto educativo em que aprender a comer com estilo é instrumento de ascensão social. Na reprodução dos habitus, os agentes se inserem num estilo de vida de classe média desenvolvendo um comportamento de tal modo incorporado que, segundo Elias, "os jovens têm apenas uma alternativa: submeter-se ao padrão de comportamento exigido pela sociedade ou ser excluídos da vida num 'ambiente decente"” (1994, p. 146).

Ao contrário das classes populares, que acabam priorizando o custo como elemento privilegiado para a escolha dos alimentos, a classe média relativiza a questão do custo para priorizar, por exemplo, um aspecto saudável como norma de bem viver. A questão 
econômica interfere mais diretamente na valorização dos alimentos para as classes mais desprovidas, visto que estas possuem mais restrições financeiras sobre o consumo. O percentual proporcional ao que é gasto com alimentos na classe média é menor do que nas famílias carentes, o que permite a escolha de um alimento entre muitas opçôes e confere status quanto mais variadas elas forem. Segundo Bourdieu, "as classes inferiores se referem, sobretudo, ao dinheiro; as classes médias, ao dinheiro e à moralidade; e as classes superiores acentuaram o nascimento e o estilo de vida" (1992, p. 24). No entanto, o elemento mais importante de distinção no estilo natural para a classe média foi o desprendimento material em termos de valor financeiro, conferindo status ao comer. $\mathrm{O}$ sentido de bem comer não está diretamente relacionado ao poder aquisitivo, a um sentido globalizado de que o comer-melhor seria o comer-mais-caro.

O quadro a seguir apresenta um desenho de pares homólogos equivalentes baseado nas posições de classe na sociedade francesa, segundo Bourdieu (1979). Os diferentes elementos de significação que formam pares são posicionados em direções opostas, indo para os extremos mais à direita ou à esquerda, mais acima ou abaixo, situando-se em relação ao elemento central alimentação natural como ponto de referência. Os elementos de significação foram construídos no próprio campo, conforme condições de possibilidades que conferem valor em intensidades diferentes na atribuição de significados e reproduzem na prática estigmas e estereótipos. Relacionar esses elementos num contexto social permite desnaturalizar e compreender o simbolismo e os sentidos no estilo natural, percebendo a flexibilidade de ser ora mais naturais, ora menos. 
Corpo esbelto sem exageros nas formas (silhueta suave)

Comida simples e trivial equilibrada

Alimentos nativos e exóticos do Brasil

Feminilidade

Mais capital cultural e status

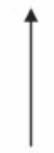

Sabor suave e refinado

— Alimentação natural

Mais capital acadêmico

Menos capital econômico

Mais status

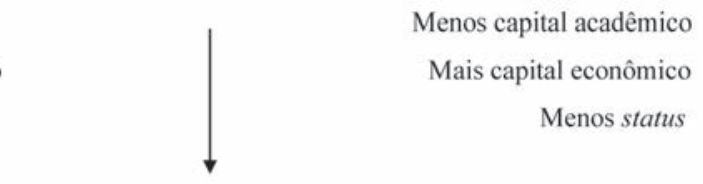

Menos capital cultural e status

Virilidade

Alimentos comerciais e industrializados em larga escala

Corpo com exageros nas formas

Comida farta tipo sustança

O estilo natural não é o único que confere distinção social à classe média. Um comportamento alimentar como o consumo de alimentos light está de acordo com isso. Entretanto, no que diz respeito ao estilo natural, não constitui um valor; ao contrário, pode representar um afastamento do natural, que tem no açúcar mascavo e no mel seus adoçantes de maior status e nos adoçantes artificiais os de menor. Por ora, vale ressaltar que o que definimos como classe média é uma categoria abstrata e variável, que não está diretamente ligada a possuir propriedades, mas ao sentido construído ao apropriar-se delas, atitude que não depende somente do valor econômico do bem material, mas do modo de apropriação subjetivo estabelecido no universo de significação dos modos à mesa e gostos alimentares nas relações sociais no interior da própria classe. 